\title{
Adult Students' Perceptions of Mobile assisted Language learning in Oral English Courses
}

\author{
La percepción de los estudiantes adultos sobre el aprendizaje de \\ idiomas asistido por dispositivos móviles en cursos orales de inglés
}

\author{
William ChARPENTIER JiMÉNEZ \\ Escuela de Lenguas Modernas \\ Universidad de Costa Rica
}

\begin{abstract}
This article explores students' perceptions on the use of certain mobile devices in an oral, English course. Mobile Assisted Language Learning (MALL) has not been widely used in language settings in the Costa Rican context. The main objective of this paper is to understand students' ideas about activities that include MALL. Results were deduced from a 10-point survey answered by students enrolled in an oral course from a major in English. The quantitative data was gathered through a survey, following survey research methods. Based on these results, the writer concludes that students consider activities using MALL a valuable asset in the learning process.
\end{abstract}

Keywords: foreign language instruction, MALL, CALL, higher education

\section{Resumen}

El presente artículo explora las percepciones de los estudiantes sobre el uso de dispositivos móviles en un curso de inglés oral. El aprendizaje de una lengua extranjera apoyado por dispositivos móviles, como Mobile-Assisted Language Learning (MALL), no ha sido ampliamente usado en contextos de aprendizaje de una lengua en Costa Rica. El principal objetivo de este artículo es comprender cómo percibe el estudiantado las actividades educativas que incluyen estos dispositivos móviles. Los datos cuantitativos se obtuvieron de una encuesta, siguiendo métodos de investigación especializados. La encuesta consistía de diez puntos y fue respondida por alumnos matriculados en un curso oral en un bachillerato en inglés. Basado en los resultados, el autor concluye que los estudiantes consideran que las actividades que utilizan MALL son un elemento invaluable en el proceso de aprendizaje.

Palabras clave: enseñanza de una lengua extranjera, MALL, CALL, educación universitaria 


\section{Introduction}

$\mathrm{T}$ his article explores students' perceptions of some MALL devices in language teaching. Several authors have explored the use of ICT in language teaching, but little is known about the use of MALL devices as part of language courses. The United Nations (2004) mentions how media and technology have become an essential part in the lives of young people and how they have become "a pedagogic force that has the potential to exceed the achievements of institutionalized forms of education" (p. 312). Additionally, the U. S. Department of Education states that technology contributes to "affirm and advance relationships between educators and students, reinvent our approaches to learning and collaboration, shrink long-standing equity and accessibility gaps, and adapt learning experiences to meet the needs of all learners" (2017, p. 3). In Costa Rica, one of the main challenges faced by the educational system is to motivate universities and educators to abandon traditional teaching methods. What is needed is to integrate TICs in the educational system at different levels (CONARE, 2017). Taking into account the global and national perspective, it becomes evident that MALL and other technologically oriented devices and applications, such as interactive computer-generated experiences and ICT, should become part of English language classes.

This research study supports the idea that students do believe that technology is an effective teaching aid. English language learners frequently rely on technological devices to find information and interact with their peers, but professors often employ methods and develop language activities that are more traditional. This mismatch opens new possibilities to explore how MALL technologies could be implemented in language teaching environments, especially oral language courses.

This analysis used a survey study design. Survey research seeks to explore opinions, attitudes, or experiences of a sample of individuals. In this case, the professor/researcher designs an activity where students use the language in a variety of ways. Then, students evaluate the activity by completing an electronic survey where they score aspects such as difficulty, the use of technology, length, among others.

As a first approach to this type of resources, this study seeks to demonstrate if students feel that technology is necessary to learn the target language faster and more efficiently and that by using technology they will improve their main skills and sub-skills. On the other hand, this study explores some MALL devices and students' preferences when learning a language. Based on these results, it is possible to prove whether newer technological experiences are attractive and beneficial to students learning English.

\section{Literature Review}

The use of technology in the field of education and applied linguistics, in particular, is not new. It was in 1983 that the term Computer Assisted Language Learning (CALL) was first used to refer to the area of technology and second language teaching and learning (Chapelle, 2001, p. 3). As the name suggests, the main focus of this field 
was to use computer programs to improve language acquisition. As technology develops, revisions for the term are suggested or added regularly. According to Jarvis and Achilleos (2013), the field of education has included Other Mobile Devices (OMDs) as a regular name for those devices that do not necessarily fit the more traditional definition of computer. Under this definition, we can find smartphones, eBook readers, and MP3 players. This, in turn, led to the acronym Mobile Assisted Language Learning (MALL) which "differs from CALL in its use of personal, portable devices that enable new ways of learning, emphasizing continuity or spontaneity of access across different contexts of use" (Kukulska-Hulme and Shields, 2008, p. 273). More recent subdivisions or applications of CALL have also emerged in the last years. Three of these newer terms are information and communication technologies, computer-generated experiences, and mobile assisted language learning. Some of the resources or activities teachers can use in the language class are defined below:

Augmented reality: "Systems that have the following characteristics: 1) combine real and virtual; 2) interactive in real time; and 3) registered in 3-D." (Mekni and Lemieux, 2014).

Intelligent Personal Assistants: "A software tool utilized by millions of consumers to interact with their smartphone, tablet, laptop or desktop computer, or smart speaker." (Neiffer, 2018, p. iii).

Jigsaw listening: "A teaching practice in which learners are responsible for learning the material and teaching it to other learners." (Karacop and Diken, 2017, p. 88).
Podcasting (video casting): (from iPod and broadcast, but not confined to the Apple iPod) the practice of preparing audio and video programs such as radio and TV broadcasts, but distributing them through the Internet for playback on MP3 players, iPods, and similar devices (Downing, et al., 2009, p. 370).

QR Codes: "Quick response codes, better known as QR codes, are small barcodes scanned to receive information about a specific topic." (Adkins, Wajciechowski, \& Scantling, 2013, p. 17).

Virtual Reality: "immersive, interactive, multi-sensory, viewercentered, three-dimensional computer-generated environments and the combination of technologies required to build these environments." (Cruz-Neira, 1993, p. 15).

These resources or activities are starting to gain a place in language teaching, and some researchers have begun exploring their potential as learning aids. Nevertheless, the majority of research has been conducted on either education in general or in fields separate from that of applied linguistics. Additionally, not a lot of research related to these specific tools or activities has been carried in the Costa Rican context. In general terms, very little research deals with how students perceive the use of technology in the language class.

Although technology has been gaining popularity in different teaching fields, newer technological devices and programs have not yet permeated the teaching system, especially in higher education. A study carried out by Crompton and Shraim (2015) evidence that although the use of mobile technologies is "on the rise, 
many academics are not effectively incorporating this technology into their teaching, which may be attributable to their negative perceptions of these devices" (p. 301). They arrived at this conclusion after compiling answers from a questionnaire filled out by 63 faculty members at a university in Palestine. The questionnaire included four- and five-point Likert-scale items, checklists, and an open-ended question dealing with the professors' perceptions of the physical attributes of mobile devices, the perceived pedagogical affordances of smart mobile devices (SMDs), and the perceived challenges of SMD's. Among the main results, Crompton and Shraim (2015) concluded that "three-quarters of respondents agreed that SMDs help faculty develop further interest in subject matter, make learning more enjoyable, meaningful and accessible" (p. 311). Professors perceive the value of technology mainly in administrative tasks such as keeping a record of grades and attendance, setting reminders, and managing calendars, among others. Nevertheless, when asked about their interest in integrating SMD's into their teaching in the future, "only $25 \%$ were very interested in doing so, 40\% somewhat interested and 35\% not interested" (p. 313). These results evidence a mismatch between what technology offers, the usual demands for more interactive and technology-oriented activities on the part of students, and what university professors find useful in educational settings. In another study on technology and its use in teaching, Russell et al. (2007) provided some reasons that illustrate why this gap exists. Their study focused on finding the relationship between teachers' technology use, tenure, and longevity. The results were figured out from a survey completed by 2,864 K-12 mathematics, English/language arts, science, social studies, and elementary classroom teachers. The survey asked teachers about the number of years in the teaching field and the number of years in the institution where they currently work. In addition, teachers were asked about their use of technology to complete different tasks, for example, to guide students in the creation of products using technology, to deliver instruction by using technology, using the e-mail for professional purposes, and using technology for preparation. In general terms, Russell et al. (2007) concluded that only in using technology for preparation, guiding students in the creation of products using technology, and using the e-mail for professional purposes did results indicate that the younger the professor, the more they used technology. On the other hand, the researchers determined that "the frequency with which teachers had students use technology during class time did not differ noticeably based on the number of years teachers were in the profession" (p. 412). The data presented in both studies point to the little use that most educators give to technology during class time. Most learners, however, seem to use technological devices such as computers or smartphones to look for information, seek entertainment, or do class-related activities.

Students' perceptions toward the use of technology in language settings have been discussed from different perspectives. Lintunen, Mutta, and Pelttari (2017) explored university students' perceptions of earlier learning in digital contexts" (p. 64). To gather the 
necessary data, the researchers conducted an online survey of 192 beginning university students majoring in languages. This online survey included demographic information, questions on out of class language learning and use of technologies, and attitude questions towards the use of technology for language learning. The researchers also used a short narrative task that focused on students' earlier education and the use of language learning technologies. The main findings of the article suggest that most students "reacted positively towards the use of technologies to enhance language learning, but there were also some critical views to emphasize the importance of inspiring contact teaching" (p. 69). In addition, Lintunen, Mutta, and Pelttari (2017) identified three digital learning profiles:

digiage learners (heavy users of especially the social media, but who have not always mixed it with learning), hybrid learners (have used technologies, but with a critical mindset, for in and out-of-school learning) and in-school learners (have used technologies, but do not believe that they facilitate the learning process) (p. 72).

The authors recommend having these profiles in mind when planning language classes. As more technology is employed as part of teaching, more profiles could become evident, and maybe more students would see the possible benefits technology brings. Stepp-Greany (2002) also investigated some possible benefits of employing different technologies in a single course. The main objectives of the study were to measure "(a) the role and importance of the instructor in technology-enhanced language learning (TELL), (b) the accessibility and relevance of the lab and the individual technological components in student learning, and (c) the effects of the technology on the foreign language learning experiences" (p. 165). Data was collected through a survey completed by 358 students learning Spanish at a university level. The survey included 45 statements and used a Lickert scale. The main questions dealt with usefulness, accessibility, effects on learning, and effects on interest and confidence that technology could bring to students. In terms of the effects on learning, the author concluded that more than $70 \%$ of students felt that they devoted more time to learning in technology-enhanced environments than in regular language classes. In terms of language skills, the researcher concluded that "almost two-thirds agreed that their listening and reading skills had improved in Spanish as a result of the lab activities $(65.9 \%$ and $63.4 \%$, respectively)" (p. 171). The author explains that results may have been influenced by the staff's experience and initial problems, such as computer glitches, planning issues, and scheduling. Technology does not operate alone and is not infallible. Studies such as the ones we have explored, however, provide important data about how professors could improve their teaching practice using technology. In the last years, with the advent of more portable and smarter devices, technology has become more ubiquitous. As explained before we have moved from Computer Assisted Language Learning to Mobile Assisted Language Learning. 
Mobile Assisted Language Learning (MALL) has become an important part of our daily lives and it has permeated language settings like never before. As a distractor, it has been frowned upon by many professors, but some others have sought ways to incorporate those devices students bring to class as allies in the teaching arena. Kim et al. (2013), for example, examined the perception of 53 graduate TESOL students when using mobile learning experiences with their own mobile devices. All data were collected through a pre-study survey, student reflections for class projects, and a post-study survey. The first survey was related to students' views on their use of personal mobile devices. Additionally, the "post-study survey scores were used as a proxy for understanding how exposure to and use of mobile technologies by a student can impact overall willingness to adopt new technology" (p. 54). To measure how students can adopt new technologies using mobile devices, researchers used the Technology Adopter Category Index (TACI). Among the various conclusions, the researchers determined that students "will change their receptivity to technological innovation (i.e., adopter category) and embrace learning with mobile technologies when they have been exposed to MLL over the length of time required to pass through the innovation-decision process" (p. 61). This was determined since there was "a statistically significant difference in individuals' TACI between the presurvey and post-survey; specifically, more participants were classified with a lower TACI in the post-survey than in the pre-survey" (p. 61). In general, having a low TACI score indicates that the user is more open about adopting technology for different purposes. This is important since some students may still be reluctant to fully adopt new technologies and would stick to more familiar types of technologies and devices. This may hinder the implementation of technology in learning settings and students' overall technological literacy in and out of class. Another study related to the use of MALL was designed by Fujimoto (2012). This study focused on the perceptions of mobile language learning of 158 university level students. The survey designed to obtain data consisted of 13 questions asking students about the devices they owned, use they gave to their devices (including learning), and their willingness to use those devices for future language learning activities. In terms of students' current use of mobile devices for learning, the researcher concluded that most learners use them for educational purposes $(70.9 \%)$ and a similar percentage of participants (70.3\%) use them specifically for language learning. About using their devices for learning purposes in the future, the researcher states that some students are not sure if they would like to use mobile devices $(12.0 \%)$; some students have a negative attitude towards this possibility (19.6\%), and most students (67.1\%) display a positive attitude towards using MALL. Some reasons provided in the study point to financial issues (data consumption) or previous negative experiences when using technology in the class. Whatever the reason might be, the advantages of technology as an aid to language teaching could bring are undeniable. Nevertheless, understanding how students view technology and its possible use in language learning 
settings in particular and education in general provide a starting point to develop activities that suit students' needs better.

This review of the literature summarizes some research on the use of technology and learning. First, a review of what professors think about technology for learning purposes reflects that faculty is usually reluctant to use technology during class. On the other hand, a majority of professors do use technology prior to or after classes, mainly for administrative purposes. Second, a general perspective about CALL and other types of technology on learning were also presented. Evidence from these studies suggests that the majority of students believe that technology-driven classes may be beneficial; however, a considerable number of students seem to harbor doubts about the use of technology in class. Finally, some perspectives on using MALL have been shown. As with CALL and other types of technology, most students acknowledge the importance of incorporating mobile devices during language classes, yet an important sector of the population seem reticent to use them or do not have a clear opinion about to what extent may technology impact learning, especially in in-class contexts.

\section{Method}

Participants. A personal electronic mailing list of a group of students $(n=25)$ taking a second-year, oral course from an English as a second language major was created during the second semester of the academic year. They were chosen since parts of the contents of the course deal with technology and its applications. The list included all students who agreed to participate in the study. All students were sent emails asking them to complete several surveys. Each survey was identical to the others, but each one asked students' opinion about one particular device or activity. The total number of surveys completed varied due to attendance. Data from these surveys were collected and analyzed. No survey was kept from analysis. In case students did not participate in a specific activity, they were not given access to the survey.

Materials. A printed written consent was created and distributed to invite students to participate. This consent was also sent to students electronically. A descriptive 10-item survey was developed to obtain information about students' perceptions of technology use in their major and their perceptions of technologically-driven activities in language classes. A copy of the survey can be found at the end of this document (Appendix 1). The survey was developed with the help of eight professors and pilot-tested with seventeen students with the same affiliation as the target population. It was later revised on the basis of the pilot-testing.

Each item on the survey was placed into one of the following two categories: (a) perceptions about the activity in general and (b) questions about the use of technology in the activity. Two question formats were used in the survey, including forced choice and at least two open-ended questions. The survey included mainly attitudinal and knowledge questions. Most items were presented as checklists or Likert scales. For example, some items asked 
the participants to indicate how important they believed the use of technology for a specific activity was. These items were rated on a 4-point Likert scale that included the following choices: $1=$ Not at All Important, 2=Slightly Important, 3=Important, and 4=Very Important. This type of scale format, or a similar one, was also used for other items in the survey.

The last part of the survey contained one open-ended question. This question invited participants to add any other comments they deemed necessary. The total time to complete the survey materials was estimated from 7 to 10 minutes.

\section{Procedure}

This study used a quantitative, survey-based study design. Initially, the researcher requested students to participate and gave them an overview of the intention of the study. In another class, after briefly explaining again the nature of the study, students were given a written consent. The researcher instructed them to read it, ask any questions they considered necessary, and sign it if they wished to participate. After collecting all the consents, a list of 25 participants was created. The first electronic mailing was sent to all 25 participants and included a digital copy of the consent. After students participated in a given activity, they received an email to be completed anonymously during class. The first activity students completed was student created podcasts. For this activity, students individually recorded themselves giving a segment of the news. The professor in charge created one single audio containing four recordings, using some extra sounds and voices to simulate a professional podcast. In the second activity, the professor explained to students what the Amazon Echo ${ }^{\mathrm{TM}}$ is and how to use it. To familiarize students with this device, they were given a chance to interact with it by asking questions of their own. Then, students listened to a preset flash-briefing of three different broadcasting companies. After taking notes on the information, students compared what they wrote to what their classmates noted. They also discussed how different or similar the news from the three broadcasting companies were. The Jigsaw Listening was the last activity. For this activity, students were in charge of part of the information provided to them with personal, portable recorders. Each recorder had a different audio segment. Students then worked in expert groups. After some discussion in those expert groups, they had to share their information in a new group where each member had different information. A total of three electronic mails were sent; each one asked students to provide their perspectives on one of the different types of activities described above.

\section{Analysis of the Results}

The following description and analysis synthesize the students' perceptions of some activities and their technological component. Questions 1 to 6 targeted general aspects of each activity. In this first part of the survey, students were asked about the clarity of instructions, how easy it was to complete the activity, length, level of difficulty, and attractiveness. 
First, students $(\mathrm{n}=22)$ participated in and provided their opinions about the activity called student-created podcasts. All students agreed or strongly agreed that instructions were clear and that the activity was easy to complete. The same is true when evaluating the length of the activity with the exception of one student who found the activity a bit long. The majority of students agreed $(n=9)$ or strongly agreed $(n=13)$ with the level of difficulty present in the activity. In relation to how interesting students found the activity, 22 students perceived the activity as interesting, whereas two students did not find the activity appealing.

The second activity participants ( $n=17$ ) completed and evaluated was the smart speaker, note-taking. A majority of students agreed $(n=2)$ or strongly agreed $(n=14)$ that the instructions were clear. Only one student disagreed with the clarity of instructions given. In terms of how easy it was to complete the activity, $10 \mathrm{stu}-$ dents strongly agreed and 5 agreed that the activity was easy to complete. Two students disagreed with this statement. When asked about the length of the activity, 8 students strongly agreed and 6 agreed that the duration of the activity was appropriate, but 3 students disagreed since they perceived it was longer than it should. The difficulty did not seem to be an issue for students. 8 students strongly agreed and 9 agreed that the level of difficulty was in accordance with their capabilities. Finally, most students ( $n=16$ ) considered the activity interesting. One participant disagreed that the activity was interesting.

The last activity completed by the participants $(n=22)$ was the jigsaw listening using portable audio players. The instructions given were clear to all the population. 3 students agreed and 19 strongly agreed with the instructions. Additionally, 7 students agreed and 15 strongly agreed that the activity was easy to complete. When considering length and difficulty, students provided the same answers. 5 students agreed and 17 strongly agreed that the duration and the difficulty of the activity were appropriate. 8 students agreed and 13 strongly agreed that the activity was interesting, while 1 student disagreed with this statement.

Further analysis was conducted to know if students had participated in similar activities in the past and if they would like to participate in similar activities in the future. Students' answers are summarized in table 1. 
Table 1

Students' Past Experiences and Willingness to Participate in Similar Activities

\begin{tabular}{|c|c|c|c|c|c|}
\hline \multicolumn{2}{|c|}{$\begin{array}{c}\text { Student-Generated } \\
\text { Podcasts }\end{array}$} & \multicolumn{2}{|c|}{$\begin{array}{c}\text { Smart Speaker Note- } \\
\text { Taking }\end{array}$} & \multicolumn{2}{|c|}{ Jigsaw Listening } \\
\hline Yes & No & Yes & No & Yes & No \\
\hline \multicolumn{6}{|c|}{ Have you participated in a similar activity before? } \\
\hline $\begin{array}{c}1 \\
(4.5 \%)\end{array}$ & $\begin{array}{c}21 \\
(95.5 \%)\end{array}$ & $\begin{array}{c}1 \\
(5.9 \%)\end{array}$ & $\begin{array}{c}16 \\
(94.1 \%)\end{array}$ & $\begin{array}{c}5 \\
(22.7 \%)\end{array}$ & $\begin{array}{c}17 \\
(77.3 \%)\end{array}$ \\
\hline \multicolumn{6}{|c|}{ Would you like to participate in similar activities in the future? } \\
\hline $\begin{array}{c}21 \\
(95.5 \%)\end{array}$ & $\begin{array}{c}1 \\
(4.5 \%)\end{array}$ & $\begin{array}{c}16 \\
(94.1 \%)\end{array}$ & $\begin{array}{c}1 \\
(5.9 \%)\end{array}$ & $\begin{array}{c}21 \\
(95.5 \%)\end{array}$ & $\begin{array}{c}1 \\
(4.5 \%)\end{array}$ \\
\hline
\end{tabular}

Source: Compiled by the author based on data gathered through students' answers.

These results demonstrate that these technologies and their corresponding activities have not made their way to language classes. On the other hand, the results of past experiences are inversely proportional to those of willingness to participate in similar activities in the future. Students seem to appreciate the inclusion of activities that break the more traditional activities in language courses.

Students were also asked how important they consider the use of technology for each activity. Smart speakers ranked as the activity where students consider technology a very important element. In this case, 1 student considered the use of technology important and 16 considered its use as very important. Students' opinions on the jigsaw listening activity resemble these results. 4 students believed the use of technology to be important and 18 agreed that the use of technology in the jigsaw listening activity was very important. Last, student-created podcasts triggered that 2 students hold that the use of technology in this activity is important. 18 students think the use of technology in this activity is very important while 2 students believe the use of technology here is slightly important.

Freeform 10 asked students to include any other comments that they consider necessary. All answers can be found in Appendix 2. Some of the most recurrent positive aspects deal with how interesting students considered the activities and how relevant these activities are for oral courses. On the other hand, students believed that the length of the activities and the quality of the audios were aspects that could be improved for future activities. 


\section{Discussion}

Advances in technology can help education overcome learning gaps and motivate students to interact with the subject matter in more dynamic ways. The results of this study provide important information about students' perceptions of the use of mobile devices to aid the language learning process. First, students perceived activities developed with mobile devices as wellstructured and pertinent. In general terms, instructions, the length of the activity, and the perceived difficulty are adequate, according to students' answers. This is important because the activity itself and the materials or technology used are interdependent. For this reason, evaluating the use of technology without taking the activity into account would be counterproductive. An aspect where the development of the activity and the use of technology work together is in developing students' interest. Although it is not possible to conclude if it is the activity or the use of technology in the activity what makes students find the activity interesting, a relationship exists since one depends on the other to arise students' enthusiasm.

Second, data shows that students have not interacted a lot with the mobile gadgets included in this research. Still, students seem very open to participating in other activities that include mobile devices. Curriculum designers, and professors who assume the task of designing activities, should decide, based on a needs analysis that includes interests, expectations, and academic needs, what other types of devices are worth including. The purpose of this paper is not to suggest that any type of device may boost students' learning; nevertheless, knowing what students' preferences are sheds some light on what mobile gadgets to incorporate and how to do it. Language programs should seek the proper balance between technology use and learning expectations while thinking about the students' needs and interests.

Third, input gathered from students advocates for the use of technology. Not only do students mention that they want more activities that include technology, but they also comment that, at least in the activities evaluated in this project, the use of technology is important. Some of the comments (Appendix 2) provided in the questionnaire reveal that students consider technology important from the academic and emotional dimensions. In the realm of language learning, these activities help students develop listening and, to a lesser degree, speaking abilities, two aspects that are paramount in oral courses. Furthermore, students label the use of technology as important because it promotes attention and interest. Students in general, and especially the younger generations, hold novelty as an essential part of the learning process, since it helps them focus and engage with the subject matter more easily.

This study has several limitations. The information is self-reported, and factors that may influence student perceptions such as student ability, prior experience with technology, prior background in English, personality type, or the relationship with the course professor were not taken into account. Additionally, the results correspond to a study of an action-research category. 
Results from this study may not be extrapolated to other similar studies with larger populations.

Future research should focus on other types of MALL devices, the extent to which these devices aid in the learning process, and the incorporation of the aforementioned activities in larger settings. First, some other newer types of technologies that deserve attention are QR's, augmented reality, and virtual reality. The applications of these technologies have not been fully described in language learning settings. Second, it is necessary to measure to what extent these activities and technologies help students acquire or improve linguistic features. Some other technologies could upgrade students' linguistic skills in different ways and to certain degrees. Last, to gather a broader insight on the possibilities of MALL, a longitudinal study may be necessary. Also, students from other cultures and age groups, and whose access to technology may vary, should be taken into account, having in mind that results will guide the design of future activities.

The researcher encourages other individuals to replicate this study. Technology evolves quickly. Students' expectations vary by the minute, and frequently, professors, technologicallyspeaking, are left behind. Since technology should be at the service of education, and in turn, education should be at the service of students, how to integrate technologies to activities should be a never-ending process where academic institutions, professors, and students become active participants in the learning process.

\section{Bibliography}

Adkins, M.; Wajciechowski, Misti R.; \& Scantling, (Ed.). (2013). The Mystery Behind the Code: Differentiated Instruction with Quick Response Codes in Secondary Physical Education. Strategies: A Journal for Physical and Sport Educators, 17-22.

Chandrasekera, T. \& Yoon, S-Y. (2018). Augmented Reality, Virtual Reality and Their Effect on Learning Style in the Creative Design Process. Design and Technology Education 23(1). Retrieved from: https://files. eric.ed.gov/fulltext/EJ1171588.pdf

Chapelle, C. (2001). Computer applications in second language acquisition. New York: Cambridge.

Consejo Nacional de Rectores. (2017). Estado de la Educación Costarricense. Retrieved from: https://www. estadonacion.or.cr/educacion2017/ assets/ee6-informe-completo.pdf

Cruz-Neira, C. (1993). Virtual Reality Overview. SIGGRAPH'93 Course, N. ${ }^{\circ} 23$.

Fujimoto, C. (2012). Perceptions of mobile language learning in Australia: How ready are learners to study on the move? The JALT CALL Journal, 8(3). Retrieved from http:// journal.jaltcall.org/articles/8_3_ Fujimoto.pdf

Jarvis, H. \& Achilleos, M. (2013). From computer assisted language learning (CALL) to mobile assisted language use (MALU). TESLEJ, 16(4).

Karacop, A. \& Diken, E. H. (2017). The Effects of Jigsaw Technique Based on Cooperative Learning on Prospective Science Teachers' Science Process Skill. Journal of Education and Practice, v. ${ }^{\circ}$, n. ${ }^{\circ} 6$. 
Kim, D.; Rueckert, D.; Kim, D-J.; \& Seo, D. (2013). Students' perceptions and experiences of mobile learning. Language Learning \& Technology, 17(3). http://dx.doi. org/10125/44339

Kukulska-Hulme, A. \& Shield, L. (2008). An overview of mobile assisted language learning: From content delivery to supported collaboration and interaction. ReCALL, 20(3).

Mekni, M. \& Lemieux, A. (2014). Augmented reality: Applications challenges and future trends. Applied Computational Science Proceedings of the 13th International Conference on Applied Computer and Applied Computational Science (ACACOS 14).

Neiffer, J. P. (2018). Intelligent Personal Assistants in the Classroom: Impact on Student Engagement. (Doctoral Dissertation). Retrieved from: https://scholarworks.umt.edu/cgi/viewcontent. cgi? article $=12295 \&$ context $=$ etd

Pekka, L.; Maarit, M.; \& Sanna, P. (2017). Profiling Language Learners in Hybrid Learning Contexts: Learners' Perceptions. The EUROCALL Review, v. ${ }^{\circ} 25$, n. $^{\circ} 1$.
Russell, M.; O'Dwyer, L.; Bebell, D.; and Tao, W. (2007). How teachers' uses of technology vary by tenure and longevity. Journal of Educational Computing Research, 37.

Shraim, K. \& Crompton, H. (2015). "Perceptions of Using Smart Mobile Devices in Higher Education Teaching: A Case Study From Palestine". Teaching \& Learning Faculty Publications, 29. https:// digitalcommons.odu.edu/teachinglearning_fac_pubs/29

Stepp-Greany, J. (2002). Student perceptions on language learning in a technological environment: Implications for the new millennium. Language Learning \& Technology, 6(1). http://dx.doi.org/10125/25148

U. S. Department of Education. (2017). Reimagining the Role of Technology in Education: 2017 National Education Technology Plan Update. Retrieved from: https://tech. ed.gov/files/2017/01/NETP17.pdf

United Nations. Department of Economic and Social Affairs (2004). World Youth Report, 2003: The Global Situation of Young People. United Nations: New York. 


\section{Appendix I Questionnaire}

Thank you very much for participating in this research project. Please complete the following information honestly and respectfully. This survey is anonymous, but, since you have the right to quit participating at any time, please include a made up name that your will use throughout the course. In case you do not want to participate any longer, please provide that name to your professor.

\section{Please write your made up name.}

For questions 1 to 9 , consider the whole activity.

1. The instructions to carry out the activity are clear.

Strongly agree

Agree

Disagree

Strongly disagree

2. The activity is easy to complete.

Strongly agree

Agree

Disagree

Strongly disagree

3. The length of the activity is appropriate.

Strongly agree

Agree

Disagree

Strongly disagree

4. I consider that the activity has the appropriate level of difficulty based on the topics and objectives of the course.

Strongly agree

Agree

Disagree

Strongly disagree

5. I consider the activity interesting.

Strongly agree

Agree

Disagree

Strongly disagree 
6. Have you ever participated in a similar activity before in any other course?
Yes
No

7. Would you like to participate in similar activities in the future in this or any other course?
Yes
No

9. The use of technology in this activity is

$\square$ Very important

Important

Slightly important

Not at all important

10. Please add any other comments that you consider necessary. 


\section{Appendix II \\ Students' comments about free-form item \#8}

\section{Smart speakers}

Interesting

I think it is very useful when it comes to improve pronunciation

It was interesting and significant. It really caught people's attention in class.

Too long

The speed of the listenings was really fast

It was a bit difficult to understand the Information giving in the news activity.

\section{Jigsaw Listening}

Interesting

The topics were interesting

I like that everyone can listen to different topics

I would have liked to have some sort of grupal discussion at the end

The volume of the audio was a little bit low

It helps to students to practice listening and to improve some weaks in listening

I found it interesting because we could know new technology problems in a different way

For me, it would be fine to listen to the audio twice in order to improve the understanding of it.

The audio was a little bit hard to understand

\section{Student-created Podcasts}

It was very interesting

It was interesting.

Too long podcast

I really like the idea of listening to ourselves and see what is good and what is bad.

There were some mistakes with the equipment that makes difficult to complete the activity

An excellent activity to implement in other courses

Enjoyable

The activity does not have any negative aspect

The quality of the audios 